\title{
Factors Affecting Children Ever Born Among Reproductive Aged Women in Ethiopia; Data from Edhs 2016
}

\author{
Zelalem Yitayal Melese ${ }^{1, *}$, Likinaw Bewuket Zeleke ${ }^{2}$ \\ ${ }^{1}$ Department of Planning, Monitoring and Evaluation, Debre Markos Referral Hospital, Debre Markos, Ethiopia \\ ${ }^{2}$ Department of Public Health, College of Health Science, Debre Markos University, Debre Markos, Ethiopia
}

Email address:

zolayitayal@gmail.com (Z. Y. Melese), bliknaw08@gmail.com (L. B. Zeleke)

${ }^{*}$ Corresponding author

To cite this article:

Zelalem Yitayal Melese, Likinaw Bewuket Zeleke. Factors Affecting Children Ever Born Among Reproductive Aged Women in Ethiopia; Data from Edhs 2016. World Journal of Public Health. Vol. 5, No. 3, 2020, pp. 66-75. doi: 10.11648/j.wjph.20200503.14

Received: October 1, 2019; Accepted: April 29, 2020; Published: September 10, 2020

\begin{abstract}
There is a great concern about the levels, patterns and trends on fertility in sub-Saharan Africa. This pattern can be affected by fertility, mortality and migration. Fertility is the key determinants of population dynamics in once country. The main objective was to identify factors affecting children ever born in Ethiopia, from EDHS 2016 data. Secondary data was used from Ethiopian Demographic Health Survey (EDHS) which was collected from January 18, 2016 to June 27, 2016. The study population was women aged 15-49 years who were living in 2007 PHC selected enumeration areas in Ethiopia. Multilevel mixed effect negative binomial regression model was applied. Completing the primary level education (IRR $=0.73$, $95 \% \mathrm{CI}=0.71-0.75$ ), completed secondary level education ( $\mathrm{IRR}=2.7995 \% \mathrm{CI}=1.69-4.60)$, place of residence (IRR=5.41, $95 \% \mathrm{CI}=3.24-9.03$ ), wealth index [poorer $(\mathrm{IRR}=0.71,95 \% \mathrm{CI}=0.52-0.98)$ and being richest $(\mathrm{IRR}=0.23,95 \% \mathrm{CI}=0.14-0.36)$ ], gaining family planning information, using family planning service and occupation had effect on the number of children ever born. Religious types and women occupation category were also found to be significantly associated factor with the number of children ever born. Factors such as age, place of residence, religion, wealth index and educational level had significant effect on the number of children ever born in Ethiopia. The recommendation forwards the government to strengthened health service focusing on family planning service in Ethiopia. Family planning information communication and advocacy strengthened by the government. Improved family planning service awareness creation conducted on the religion aspects. The community participate in family planning health service, increase participation in education and listened information about family planning from different source. For the researcher, to do further researches to answered why these significant factor affect number of children ever born in Ethiopia.
\end{abstract}

Keywords: Children Ever Born, Mixed Effect Negative Binomial Regression, Reproductive Aged Women

\section{Background}

Children ever born for women in her life time is the average number of children born till the data were collected. Children ever born for a women means that a measure of her life time fertility get up to the motion in which the data are collected [1]. In most cases, the average number of children ever born is computed the ratio of the number of children born alive to all women in a particular age group to the number of women [2]. Children ever born includes who have died after birth but does not include stillbirth, abortion or child adopted by the individual [3].
World's population increase is driven by high fertility in sub-Sahara Africa whose population is forecast to more than double in the next 40 years. According to 2015 revision of World population prospects, total fertility is now 2.5 children per women globally. Africa remains the region with the highest fertility at 4.7 children per women $[4,5]$. There is a great concern about the levels, patterns and trends on fertility in sub-Saharan Africa. This pattern can affect by fertility, mortality and migration. Of the mentioned factors fertility is the key determinants of population dynamics in once country [6].

With the thought of conventional demographic theory, high fertility in the early stage of demographic transition is the 
consequence of high desired family size. Couples want many children to assist with family enterprises such as farming and for security in old age. In addition, high child mortality leads parent to have more additional children to protect against loss or to replaces loss. Fertility decline occurs when rising level of urbanizations and education, change in economy, and decreasing mortality lead to parents to desire a smaller number of children/births [7].

In Ethiopia, the average children ever born per women was 4.6 in 2015 which is higher from the worlds average number of children ever born per women. This number is affected by a number of socio-psychological and economic variables. Beside the biological capacity of reproduction considerable differences were found between actual fertility levels and desired family size in all the sociodemographic variables [8, 9].

Children ever born (CEB) is one of the three main factors of population dynamics to determine the size, structure, and composition of the population in any country [10]. The world population size increase time to time even though different activities tried to decrease the increment [11]. Ethiopia is one of the country in which the size of the population is increase in each census. When we see the figure of 2007 census, it had 20.8 million increment from 1994 census population size [12]. This increment has different causes which include number of children ever born. This ever born children also has its own factors for the increment or decrement variability [13].

Research conducted in Nepal identified the causes of children ever born variability which include age at marriage, occupation of husband and family planning understanding [10]. According to 2012 fertility estimation Ethiopia accounted for 4.6 children per woman and according to 2017 estimation the population can reach around 100,613,986 [12]. Based on the research which was conducted in Botswana; residence, marital status and age of women had significant effect on fertility whereas education and fertility had inversely relationships [3]. But, in EDHS 2016 these variable did not examined whether they had effect on fertility or not. So, this research will fulfill this gap by analyzing the variables.

Analytical report on the title of Fertility and Marriage Patterns in Republic of Liberia revealed that occupation, religion and Ethnicity has significant effect on fertility rate. Even though, it deals about total fertility which differs from this paper which focus on reproductive age fertility [14]. However, the EDHS 2016 analysis address the descriptive analysis of reproductive age, is did not identified the listed variables had effect or not on the children ever born in the reproductive age.

Though, Ethiopia have implemented policies and strategies to promote family planning and achieve subsequently experienced lower birth rates at faster pace than other countries still the birth rate was not declined in the global expected average. Currently, 214 million women in developing countries who wish to avoid pregnancy but are not currently using any form of contraceptive. This leads women and couples who wish to have fewer children are unable to determine the size of their families in large part due to lack of family planning funding from abroad and an overall lack of resources more abroad [15]. This unmet need of contraceptive can be occurred due to lack of knowledge, source of supply, low quality and low availability of the methods, cost of travel and time, heath status, objection from husbands and concerns about the social acceptability. These factor contribute for the women to lead unwanted pregnancy which implies have birth without the women preferences [7].

As Wikipedia, in many countries having fewer children has come about as s response to increased life expectancy, reduced childhood mortality, improve female literacy and independence, and urbanization that all results from increased GDP per capita [16]. The economic theories about declining fertility postulate that people earning more have higher opportunity cost if they focus on childbirth and parenting rather than continuing their career, that women who can economically sustain themselves have less incentive to become married, and that higher income parents value quality over quantity and so spend their resources on fewer children [17].

Ethiopia stipulated the National Population Policy by the year 1993 with the specific objective of reducing fertility rate from 7.7 children per women to approximately 4.0 per women by the year 2015 by performing training of family planning workers and others [18]. But, in Ethiopia still the number of children ever born per women in average reported beyond the planned. In EDHS 2016 fertility preference, age of mother, residence, education and wealth quantile were analyzed descriptively. However, all the above mentioned factors displayed as coverage descriptively, factors which influence children ever born did not identified in that survey.

\section{Methods}

\section{Study Design}

For this study a cross-sectional EDHS 2016 data was used. Study Area and Period

Ethiopia, bordered by Eritrea, Djibouti, Kenya, South Sudan and Sudan, Somalia, is one of the country which are found in the horn of Africa sub-Sahara region. The country has 9 administrative regional states and 2 administrative cities [19]. Ethiopia has a total estimation population of $112,936,000$ of which $36,621,848(32.42 \%)$ are females. Population age group 15-64 years accounts 51.9\% and 0-14 age accounts $45 \%[8,12]$.

The average children ever born per women was 4.6 in 2015 which is higher from the world's average number of children ever born per women [8]. Age specific fertility rate measurement revealed that the highest number of children ever born was in age group of 25-29 years which was 224 children per thousand women [4]. This study was conducted by using secondary data of EDHS 2016 in Ethiopia which was collected from January 18, 2016 to June 27, 2016 by the Central Statistics Agency of Ethiopia.

Population 


\section{Source Population}

The source population was Ethiopian women aged 15-49 years.

\section{Study Population}

The study population for this research were number of women with age group of 15-49 years who found in selected enumeration areas.

\section{Eligibility Criteria}

\section{Inclusion Criteria}

All women who were either permanent residents of the selected households or visitors who stayed in the household the night before the survey were included in EDHS 2016.

Sample Size Determination and Procedure

\section{Sample Size Determination}

The sampling frame used for the 2016 EDHS is the Ethiopia Population and Housing Census (PHC), which was conducted in 2007 by the Ethiopia Central Statistical Agency (CSA). The census frame is a complete list of 84,915 enumeration areas (EAs) created for the 2007 PHC. An EA is a geographic area covering on average of 181 households. The sampling frame contains information about the EA location, type of residence (urban or rural), and estimated number of residential households. With the exception of EAs in 6 zones of the Somali region, each EA has accompanying cartographic materials.

These delineate geographic locations, boundaries, main access, and landmarks in or outside the EA that help to identify the EA. In Somali, cartographic frames were used in three zones, where a sketch map that delineates the EA geographic boundaries is available for each EA; in the remaining six zones, satellite image maps were used to provide a map for each EA. The sample for the 2016 EDHS was designed to provide estimates of key indicators for the country as a whole, for urban and rural areas separately, and for each of the nine regions and the two administrative cities [20].

\section{Sampling Procedure}

The 2016 EDHS sample was stratified and selected in two stages. Each region was stratified into urban and rural areas, yielding 21 sampling strata. Samples of EAs were selected independently in each stratum in two stages. Implicit stratification and proportional allocation were achieved at each of the lower administrative levels by sorting the sampling frame within each sampling stratum before sample selection, according to administrative units in different levels, and by using a probability proportional to size selection at the first stage of sampling.

In the first stage, a total of 645 EAs (202 EAs in urban areas and 443 EAs in rural areas) were selected with probability proportional to the EA size (based on the 2007 PHC) and with independent selection in each sampling stratum. A household listing operation was carried out in all the selected EAs from September to December 2015. The resulting lists of households served as a sampling frame for the selection of households in the second stage. Some of the selected EAs were large, with more than 300 households. To minimize the task of household listing, each large EA selected for the 2016 EDHS was segmented. Only one segment was selected for the survey, with probability proportional to the segment size. Household listing was conducted only in the selected segment, that is, a 2016 EDHS cluster is either an EA or a segment of an EA. In the second stage of selection, a fixed number of 28 households per cluster were selected with an equal probability systematic selection from the newly created household listing [20].

Variables of the Study

Dependent Variable

Children ever born.

Independent Variables

The independent variables for this research were Sociodemographic related (Age of women, Occupation of women, Education level of women, Marital status, Age at first sex, Residence, Religion), Family planning related factors (information about family planning, using of family planning and knowledge of family planning), Socio-economic related factors (Wealth index) and Fertility preference related factors.

Operational Definitions

1. Children ever born=Number of children born by a woman in till the data were collected.

2. Wealth index=is a composite measure of household's cumulative living standards.

3. Knowledge of any family planning method=Knowledge of any method is classified into modern, traditional and folkloric methods as follows: Modern methods are Pill, IUD, Injections, Diaphragm, Condom, Female Sterilization, Male Sterilization, Implants, Lactational Amenorrhea, Female Condom, Foam and Jelly, Emergency Contraception and the category "other modern method". Traditional methods are Periodic Abstinence (Rhythm), Withdrawal, and Abstinence. Folkloric methods are the category "other traditional method". If a respondent knows both a traditional method and a modern method then the modern method takes priority and she is coded as knowing a modern method. Similarly, if a woman knows a traditional method and a folkloric method, the traditional method takes priority.

4. Not working=woman doesn't work as an employee in Government or private organization.

5. Family planning information=gaining of information about family planning from any source of information.

6. Family planning user- use of of any method is classified into modern, traditional and folkloric methods as follows: Modern methods are Pill, IUD, Injections, Diaphragm, Condom, Female Sterilization, Male Sterilization, Implants, Lactational Amenorrhea, Female Condom, Foam and Jelly, Emergency Contraception and the category "other modern method". Traditional methods are Periodic Abstinence (Rhythm), Withdrawal, and Abstinence. Folkloric methods are the category "other traditional method". If a respondent knows both a traditional method and a modern method then the modern method takes priority and she is coded as knowing a modern method. Similarly, if a woman 
knows a traditional method and a folkloric method, the traditional method takes priority.

Data Extraction Procedures

The study was used secondary data sources which was EDHS 2016 data. To access this data first requesting the DHS program data archivist by develop summarized proposal was held. After a while the organization was gave confirmation letter to access and to did this thesis on the mentioned title. Coherently EDHS data was delivered in seven file records. These file records were house hold record file, house hold member record file, individual/women record file (IR), men record file, child record file, birth record file and couple record file. Among these the convenient record file which was individual record file was selected for this paper. In the IR file record eligible women aged 15-49 years were included with 5704 variables and 15683 participants. Mean a while in this IR file the suggested independent variables also identified for the thesis based on the finding of literature review after detailed reading and understanding of the data and variables. To be clear about each variable description the DHS standard record manual was used as guide-line. Survey data weighting was done by using the women's individual weight sample, primary sampling unit and sampling strata of the survey.

Data Analysis and Model Selection Techniques

The data were already entered in Stata and SPSS by the DHS programed organization. From all 5704 variables, independent variables were selected for the analysis. After identified variables the type of data, labeling and the value given were cleared. Then, these selected independent variables were separated from all variables. The survey data set was declared as survey design before going to the analysis. These collected and separated data was analyzed using STATA V 14.0 as in descriptive (frequency, percentage, tables, mean, median and standard deviation) to clarify the independent variables and dependent variable.
Poisson model was tried to apply since the response variable was a count variable. Independent assumption was considered and presence of correlation was also checked by estimating intraclass correlation coefficient (ICC) since the data was hierarchical and clustered. As the same time by estimated ICC result implied to use multilevel analysis (mixed effect negative binomial regression) was considered. The data showed that there were correlation at clustered level that obligate to use multilevel analysis model. Then through model comparison, the model with EA cluster level was best fitted model for the data. Over-dispersed and excessive number of zeros was examined. After all mixed effect negative binomial regression model was the choice model for this analysis. Stepwise backward negative binomial regression was applied at $\mathrm{p}$-Value $<0.25$ to select variables for multivariable mixed effect negative binomial regression. Variance estimation was done by considering EA has clustering effect. Based on Akaike information criteria (AIC) result used to select the final fitted model. Likelihood ratio test vs. negative binomial model was significant at $\mathrm{Chi}^{2}$. $<0.001$. Offset variable was considered. For bi-variable mixed effect negative binomial regression $\mathrm{P}$-value $<0.25$ at 95\% CI was taken as a significant and $\mathrm{P}$-value $<5 \%$ at $95 \% \mathrm{CI}$ was takes as significant value for multivariable mixed effect negative binomial regression.

Limitation of the Study

It is known that the data already collected by pre-prepared questionnaire by the responsible organization so it was difficulty of gaining exact variable data and, there was multiple categorizing and using common operational definitions.

\section{Results}

Socio-demographic and socio-economic characteristics.

Table 1. Socio-demographic and socio-economic characteristics of factors affecting number of children ever born among reproductive aged women in Ethiopia; data from EDHS 2016; formulated by researcher, 2019.

\begin{tabular}{|c|c|c|c|c|}
\hline Variables & & $\mathbf{N}$ & $\%$ & Pearson chi2 with CEB \\
\hline \multirow{8}{*}{ Age } & $15-19$ & 3,498 & 22.3 & \multirow{18}{*}{ Pearson chi2 $(112)=910.08 \mathrm{Pr}=<0.001$} \\
\hline & $20-24$ & 2,903 & 18.51 & \\
\hline & $25-29$ & 2,845 & 18.14 & \\
\hline & $30-34$ & 2,241 & 14.29 & \\
\hline & $35-39$ & 1,917 & 12.22 & \\
\hline & $40-44$ & 1,302 & 8.3 & \\
\hline & $45-49$ & 977 & 6.23 & \\
\hline & Total & 15,683 & 100 & \\
\hline \multirow{10}{*}{ Occupation in grouped } & Not working & 8,045 & 51.3 & \\
\hline & Professional/technical/managerial & 494 & 3.15 & \\
\hline & Clerical & 211 & 1.35 & \\
\hline & Sales & 2495 & 15.91 & \\
\hline & Agricultural - employee & 2637 & 16.81 & \\
\hline & Services & 528 & 3.37 & \\
\hline & Skilled manual & 593 & 3.78 & \\
\hline & Unskilled manual & 279 & 1.78 & \\
\hline & Others & 401 & 2.56 & \\
\hline & Total & 15,683 & 100 & \\
\hline
\end{tabular}




\begin{tabular}{|c|c|c|c|c|}
\hline Variables & & $\mathbf{N}$ & $\%$ & Pearson chi2 with CEB \\
\hline \multirow{5}{*}{$\begin{array}{l}\text { Highest Educational } \\
\text { Level }\end{array}$} & No education & 7033 & 44.84 & \multirow{5}{*}{ Pearson chi2 $(42)=5.0 \mathrm{e}+03 \mathrm{Pr}=<0.001$} \\
\hline & Primary & 5213 & 33.24 & \\
\hline & Secondary & 2238 & 14.27 & \\
\hline & Higher & 1199 & 7.65 & \\
\hline & Total & 15683 & 100 & \\
\hline \multirow{7}{*}{ Religion } & Orthodox & 6,413 & 40.89 & \multirow{7}{*}{ Pearson chi2 $(70)=532.05 \operatorname{Pr}=<0.001$} \\
\hline & Catholic & 91 & 0.58 & \\
\hline & Protestant & 2,814 & 17.94 & \\
\hline & Muslim & 6,209 & 39.59 & \\
\hline & Traditional & 84 & 0.54 & \\
\hline & Other & 72 & 0.46 & \\
\hline & Total & 15,683 & 100 & \\
\hline \multirow{3}{*}{ Place of residence } & Urban & 5,348 & 34.1 & \multirow{3}{*}{ Pearson chi2 $(14)=1.6 \mathrm{e}+03 \mathrm{Pr}=<0.001$} \\
\hline & Rural & 10,335 & 65.9 & \\
\hline & Total & 15,683 & 100 & \\
\hline \multirow{6}{*}{ Wealth index } & Poorest & 3,894 & 24.83 & \multirow{6}{*}{ Pearson chi2 $(56)=1.8 \mathrm{e}+03 \mathrm{Pr}=<0.001$} \\
\hline & Poorer & 2,046 & 13.05 & \\
\hline & Middle & 2,002 & 12.77 & \\
\hline & Richer & 2,042 & 13.02 & \\
\hline & Richest & 5,699 & 36.34 & \\
\hline & Total & 15,683 & 100 & \\
\hline
\end{tabular}

The large number of respondents' age lined in the age category of $15-19$ years $(22.3 \%)$ and the median age of the respondents' was 27 years. one out of four women started their first sexual practices in the age of 15-16 ears (mean age of 12.9). In terms of women occupation, $51.3 \%$ of the respondents' were not working. The participants' educational level indicated that $44.8 \%$ not educated. Orthodox religion was the leading religion which figures $44.8 \%$. Respondents live in the rural area were $65.9 \%$ and $36.3 \%$ of the respondents found in the wealth index category of richest.

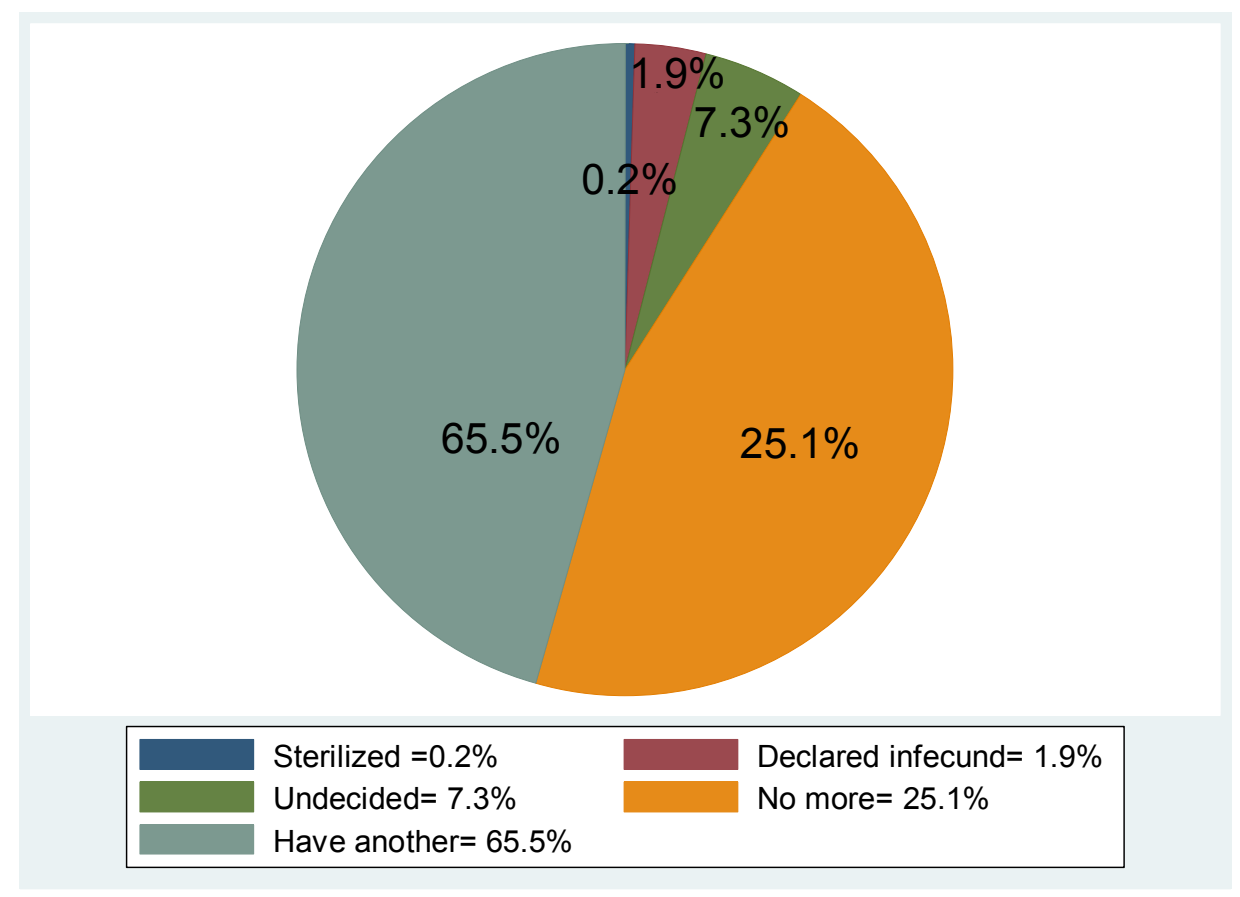

Figure 1. Pie graph fertility preferences in factors affecting number of children ever born among reproductive age women in Ethiopia; data from EDHS 2016; formulated by researcher, 2019.

Figure 1 indicated that women had no child accounts $34.5 \%$; in other hand, women had minimum one and maximum 14 children accounts $65.5 \%$. From all children $52 \%$ of child sex was male. In Figure 1 also, the fertility preference of the respondent showed that $65.5 \%$ prefer to have another children but $0.9 \%$ were sterilized.

Results Related to Family Planning Variables 
Table 2. Family planning related variables on factors affecting number of children ever born among reproductive age women in Ethiopia; data from EDHS 2016; formulated by researcher, 2019

\begin{tabular}{|c|c|c|c|c|}
\hline Variables & & $\mathbf{N}$ & $\%$ & Pearson $\mathrm{Chi}^{2}$ \\
\hline \multicolumn{5}{|c|}{ Knowledge of any family planning method } \\
\hline & Knows no method & 79 & 4.52 & \multirow{4}{*}{ Pearson chi2 $(28)=94.42 \operatorname{Pr}=<0.001$} \\
\hline & Knows only traditional method & 11 & 0.07 & \\
\hline & Knows modern method & 14,963 & 95.41 & \\
\hline & Total & 15,683 & 100 & \\
\hline \multicolumn{5}{|l|}{ Family planning use } \\
\hline \multirow{3}{*}{ Current user } & Yes & 256 & 1.92 & \multirow{3}{*}{ Pearson chi2 $(14)=127.16 \operatorname{Pr}=<0.001$} \\
\hline & No & 13,084 & 98.08 & \\
\hline & No & 9,798 & 62.48 & \\
\hline \multirow{3}{*}{ Ever user } & Yes, used outside calendar & 609 & 3.88 & \multirow{3}{*}{ Pearson chi2 $(28)=2.2 \mathrm{e}+03 \mathrm{Pr}=<0.001$} \\
\hline & Yes, used in calendar & 5,276 & 33.64 & \\
\hline & Total & 15,683 & 100 & \\
\hline \multicolumn{5}{|c|}{ Sources of information for Family planning } \\
\hline & Yes & 3,995 & 25.47 & \multirow{4}{*}{ Pearson chi2 $(14)=484.65 \operatorname{Pr}=<0.001$} \\
\hline \multirow[t]{3}{*}{ Radio } & No & 11,688 & 74.53 & \\
\hline & Total & 15,683 & 100 & \\
\hline & Yes & 4,089 & 26.07 & \\
\hline \multirow[t]{3}{*}{ Television } & No & 11,594 & 73.93 & \multirow[t]{2}{*}{ Pearson chi2 $(14)=1.3 \mathrm{e}+03 \mathrm{Pr}=<0.001$} \\
\hline & Total & 15,683 & 100 & \\
\hline & Yes & 1,008 & 6.43 & \multirow{3}{*}{ Pearson chi2 $(14)=406.16 \mathrm{Pr}=<0.001$} \\
\hline \multirow[t]{3}{*}{ Newspaper/Magazine } & No & 14,675 & 93.57 & \\
\hline & Total & 15,683 & 100 & \\
\hline & Yes & 361 & 2.3 & \multirow{3}{*}{ Pearson chi2 $(14)=81.05 ; \operatorname{Pr}=<0.001$} \\
\hline \multirow[t]{2}{*}{ Mobile Text Message } & No & 15,322 & 97.7 & \\
\hline & Total & 15,683 & 100 & \\
\hline
\end{tabular}

About $95 \%$ of respondents' had known modern family planning methods. But, $0.07 \%$ of participants had known about traditional family planning methods. Family planning user were ever users and current users which were $37.5 \%$ and $1.9 \%$ respectively. Using family planning methods ever or current and children ever born had shown associations which tested by the Pearson chi2 $\mathrm{Pr}=<0.001$ and Pearson chi2 $\operatorname{Pr}=<0.001$ in respectively.

The sources of information about family planning were different for the participants. So, Information gained from radio $25.5 \%$, from television $26 \%$, from newspaper/magazine $6.4 \%$ and from mobile text $2.3 \%$. Even though, the sources of information about family planning being different, all sources of media had association measured by pearson chi2 test.

Factors affecting number of children ever born among reproductive aged women in Ethiopia; data from EDHS 2016

The statistical model mixed effect negative binomial regression model was applied. Variance across cluster and region was estimated. Zero inflation and zero inflated negative binomial regression model checked result were displayed. In table 1 the mean (2.63) and variance (8.1) which is the square of standard deviation (2.84) had high difference that indicates over dispersion and this leads rejecting of Poisson regression model and chosen negative binomial regression model.

Table 3. Mean and variances on factors affecting number of children ever born among reproductive age women in Ethiopia, data from EDHS 2016; by researcher, 2019.

\begin{tabular}{llllll}
\hline Sum CEB & & & & & \\
\hline Variable & Obs & Mean & Std. Dev. & Min & Max \\
\hline CEB & 15,683 & 2.639291 & 2.841411 & 0 & 14 \\
\hline
\end{tabular}

Table 4. Intra-class correlation on region or cluster (PSU) on factors affecting number of CEB among reproductive age women in Ethiopia, data from EDHS 2016; by researcher, 2019.

\begin{tabular}{lllll}
\hline estat icc & & & & \\
\hline Intraclass correlation & & & & \\
\hline Level & ICC & Std. Err. & [95\% Conf. Interval] & \\
\hline Region & .0618598 & .0249977 & .0275643 & .13299 \\
Level & ICC & Std. Err. & {$[95 \%$ Conf. Interval] } & .1531631 \\
Primary SU (V21) & .1356244 & .0085002 & .1198098 & \\
\hline
\end{tabular}

Table 5. Bi-variable and multivariable mixed effect negative binomial regression result on factors affecting number of children ever born among reproductive aged women in Ethiopia; data from EDHS 2016; by researcher, 2019.

\begin{tabular}{|c|c|c|c|c|c|c|c|}
\hline \multirow{2}{*}{ CEB } & \multicolumn{3}{|c|}{ C. IRR } & \multicolumn{4}{|c|}{ A. IRR } \\
\hline & IRR & {$[95 \%$} & & IRR & $\mathbf{P}>|\mathbf{z}|$ & {$[95 \%$} & \\
\hline Age at first sex & 0.97 & 0.95 & 0.99 & 0.98 & 0.31 & 0.96 & 1.01 \\
\hline $\begin{array}{l}\text { Education completed (Ref. Higher educated) } \\
\text { not educated }\end{array}$ & 13.35 & 9.38 & 19.00 & 0.22 & $<0.001$ & 0.13 & 0.37 \\
\hline
\end{tabular}




\begin{tabular}{|c|c|c|c|c|c|c|c|}
\hline \multirow{2}{*}{ CEB } & \multicolumn{3}{|l|}{ C. IRR } & \multicolumn{4}{|c|}{ A. IRR } \\
\hline & \multirow{2}{*}{$\begin{array}{ll}\text { IRR } \\
65.78\end{array}$} & \multicolumn{2}{|c|}{$[95 \% \mathrm{CI}]$} & \multirow{2}{*}{$\begin{array}{l}\text { IRR } \\
3.46\end{array}$} & \multirow{2}{*}{$\begin{array}{l}\mathbf{P}>|\mathbf{z}| \\
<0.001\end{array}$} & \multicolumn{2}{|l|}{$[95 \% \mathrm{CI}]$} \\
\hline Primary & & 45.75 & 94.59 & & & 2.14 & 5.59 \\
\hline Secondary & 19.48 & 12.86 & 29.51 & 2.79 & $<0.001$ & 1.69 & 4.60 \\
\hline \multicolumn{8}{|l|}{ Place of residence (Ref. urban) } \\
\hline Rural & 9.81 & 7.99 & 12.04 & 5.41 & $<0.001$ & 3.24 & 9.03 \\
\hline \multicolumn{8}{|l|}{ Wealth index comb (Ref. poorest) } \\
\hline Poorer & 0.59 & 0.45 & 0.79 & 0.71 & 0.04 & 0.52 & 0.98 \\
\hline Middle & 0.47 & 0.35 & 0.63 & 0.47 & $<0.001$ & 0.34 & 0.67 \\
\hline Richer & 0.23 & 0.17 & 0.31 & 0.26 & $<0.001$ & 0.19 & 0.38 \\
\hline Richest & 0.06 & 0.05 & 0.08 & 0.23 & $<0.001$ & 0.14 & 0.36 \\
\hline \multicolumn{8}{|l|}{ Women Occupation (Ref. not working) } \\
\hline Professional/technical/managerial & 0.01 & 0.01 & 0.02 & 0.08 & $<0.001$ & 0.04 & 0.15 \\
\hline Clerical & 0.01 & 0.002 & 0.01 & 0.08 & $<0.001$ & 0.03 & 0.21 \\
\hline Sales & 0.10 & 0.07 & 0.13 & 0.27 & $<0.001$ & 0.20 & 0.35 \\
\hline Agricultural employee & 0.30 & 0.23 & 0.39 & 0.26 & $<0.001$ & 0.20 & 0.34 \\
\hline Services & 0.16 & 0.09 & 0.29 & 0.41 & $<0.001$ & 0.23 & 0.73 \\
\hline Skilled manual & 0.15 & 0.09 & 0.24 & 0.45 & $<0.001$ & 0.28 & 0.72 \\
\hline Unskilled manual & 0.24 & 0.11 & 0.51 & 0.31 & $<0.001$ & 0.15 & 0.65 \\
\hline Others & 0.06 & 0.03 & 0.10 & 0.16 & $<0.001$ & 0.09 & 0.30 \\
\hline \multicolumn{8}{|l|}{ Knowledge of FP (Ref. knows no method) } \\
\hline Knows only traditional method & 3.54 & 0.05 & 225.58 & 0.52 & 0.23 & 0.001 & 6.55 \\
\hline Knows modern method & 0.31 & 0.20 & 0.48 & 1.02 & 0.91 & 0.63 & 1.66 \\
\hline \multicolumn{8}{|l|}{ Religion (Ref. orthodox) } \\
\hline Catholic & 3.89 & 1.28 & 11.84 & 2.12 & 0.018 & 0.69 & 6.55 \\
\hline Protestant & 3.49 & 2.69 & 4.54 & 1.82 & 0.01 & 1.28 & 2.58 \\
\hline Muslim & 8.09 & 6.57 & 9.89 & 5.20 & $<0.001$ & 3.79 & 7.11 \\
\hline Traditional & 5.28 & 1.67 & 16.69 & 5.70 & 0.03 & 1.19 & 27.31 \\
\hline Other & 7.68 & 2.23 & 26.46 & 3.92 & 0.03 & 1.17 & 13.12 \\
\hline $\begin{array}{l}\text { FP Information gained ( Ref. didn't gained FP } \\
\text { information) }\end{array}$ & 0.19 & 0.15 & 0.23 & 0.54 & $<0.001$ & 0.43 & 0.69 \\
\hline Not FP User (Ref. FP user) & 0.58 & 0.48 & 0.69 & 4.53 & $<0.001$ & 3.62 & 5.65 \\
\hline \multicolumn{8}{|l|}{ Fertility Preferences (Ref. have more) } \\
\hline Undecided & 0.12 & 0.08 & 0.20 & 0.19 & $<0.001$ & 0.12 & 0.29 \\
\hline No more & 0.05 & 0.045 & 0.68 & 0.06 & $<0.001$ & 0.04 & 0.07 \\
\hline Sterilized (respondent or partner) & 0.01 & 0.00 & 0.001 & 0.001 & $<0.001$ & 0.001 & 0.006 \\
\hline Declared infecund & 0.0001 & 0.0003 & 0.001 & 0.0001 & $<0.001$ & 0.0001 & 0.0004 \\
\hline Offset variable (women age) & & & & & & & \\
\hline
\end{tabular}

On the bi-variable mixed effect negative binomial regression analysis by taking women age as an offset variable; age at first sex, completed one of the categorized education level, gaining family planning information, used family planning service or the method, wealth index, religion, occupation and knowledge of family planning had effect on the number of children ever born. When saw fertility preference variables prefer to no more children was a significant factor for the number of children ever born among reproductive aged women in Ethiopia. In multivariable mixed effect negative binomial regression different variables showed different results with different incidence rate ratio, $\mathrm{p}$-value and $95 \% \mathrm{CI}$ with women age taking as offset variable. Generally, for the interpretation and discussion section the adjusted incidence rate ratio (A. IRR), P-value with CI was taken. Educational level had its own decrement effect on the number of children ever born. I.e.; Completed the primary level education $I R R=3.46$ $(95 \% \mathrm{CI}=0.13-0.37)$ means that women completed their primary level education, number of children ever born increased by $46 \%$ when compared with that of completed their higher education, while holding all other variables in the model constant in Ethiopia based on EDHS 2016 data. Completed secondary level education $I R R=2.79$
$(95 \% \mathrm{CI}=1.69-4.60)$ means that completed secondary level education increase number of children ever born by $79 \%$ when compared to that of completed higher education level. No education $\mathrm{IRR}=0.22(95 \% \mathrm{CI}=0.13-0.37)$, which implies that when the women were not educated, number of children ever born decreased by $78 \% \%$ when compared to that of completed higher education, while holding all other variables in the model constant. Place of residence (living in rural) has a significant influence on the number of children ever born, increased which showed as IRR $=5.41$ (95\% CI $=3.24-9.03)$. This implies that when compared women living in rural to that of urban, living in rural increase the number of children ever born by $41 \%$ when compared to living urban. When see the wealth index factor the poorer IRR $=0.71(95 \% \mathrm{CI}=0.52-0.98)$, which means that being poorer decrease the number of children ever born by $29 \%$ when compared with poorest. Having middle wealth index $\mathrm{IRR}=0.47 \quad(95 \% \mathrm{CI}=0.34-0.67)$, which means that having middle wealth index decrease the number of children ever born by $53 \%$ when compared with poorest. Richer which result IRR $=0.26(95 \% \mathrm{CI}=0.19-0.38)$, which means that being richer decrease the number of children ever born by $74 \%$ when compared with poorest. Richest with the result IRR $=0.23(95 \% \mathrm{CI}=0.14-0.36)$, which means 
that being richest decrease the number of children ever born by $77 \%$ when compared with poorest.

Factors related to women occupation category showed an effect on the dependent variable. Women work professional/technical/managerial job had $\mathrm{IRR}=0.08$ (95\%CI=0.04-0.15), which implies that when women had professional/technical/managerial job number of children ever born decrease by $92 \%$ than women had no their own work. Women work clerical job had a result of IRR $=0.08$ (95\% CI $=0.03-0.21)$, which implies that when women having their own clerical work number of children ever born decrease by $92 \%$ than women had no their own work. Women who engaged on sales job had IRR $=0.27$ (95\% CI $=0.20-0.35)$, which implies that when women having their own sales work decrease number of children ever born by $73 \%$ than women had no their own work, while holding all other variables in the model constant. Women who work in giving service job had $\mathrm{IRR}=0.41$ (95\% CI $=0.23-0.73)$, which implies that when women work in service giving decrease number of children by $59 \%$ than women had no their own work. Women who work in skilled manual job had $\mathrm{IRR}=0.45 \quad(95 \% \mathrm{CI}=0.28-0.72)$, which implies that when women work in skilled manual job decrease number of children ever born by $55 \%$ than women had no their own work. Women who work in unskilled manual job had $\mathrm{IRR}=0.31 \quad(95 \% \mathrm{CI}=0.15-0.65)$, which implies that when women work in unskilled manual job decrease number of children ever born by $69 \%$ than women had no work. Religion is reported as one of the significant factor which associated with the number of children ever born. Protestant religion of $\mathrm{IRR}=1.82(95 \% \mathrm{CI}=1.28-2.58)$ means that being Protestant religious women increase the number of children ever born by $82 \%$ when compared with orthodox religious women. Muslim with $\mathrm{IRR}=5.20$ $(95 \% \mathrm{CI}=3.79-7.11)$ means that being Muslim religious women increase the number of children ever born by $20 \%$ when compared with that of orthodox religious women. Traditional religious women with $\mathrm{IRR}=5.70(95 \% \mathrm{CI}=1.19$ 27.31) means that being Traditional religious women increase the number of children ever born by $70 \%$ when compared with orthodox religious women. Other religious women with $\mathrm{IRR}=3.92(95 \% \mathrm{CI}=1.17-13.12)$ means that women had other religious increase the number of children ever born by $92 \%$ when compared with orthodox religious women.

Had family planning information with $I R R=0.54$ (95\%CI $=0.43-69)$, means that women had family planning information decrease the number of children ever born by $46 \%$ when compared with that of women had no family planning information. Not family planning users with $\mathrm{IRR}=4.53(95 \% \mathrm{CI}=3.62-5.65)$, indicated that women were not being family planning users increase the number of children ever born by $47 \%$ when compared with that of women were family planning users. On the results of this research the fertility preference also a significant factor on the number of children ever born. Women who were undecided about her preference to bearing child with
$\mathrm{IRR}=0.19(95 \% \mathrm{CI}=0.12-0.29)$ indicated that women that were undecided about her fertility preference decreased the number of children ever born by $89 \%$ when compared with women decide to have more children. Have no more children was a factor with $\mathrm{IRR}=0.06(95 \% \mathrm{CI}=0.04-0.07)$.

\section{Discussions}

Children ever born (CEB) is one of the three main factors of population dynamics to determine the size, structure, and composition of the population in any country. This CEB can be affected by different factors which mentioned next detail from the finding of this thesis. This factor can be classified as socio-demographic, socio-economic, fertility preference and family planning related factors.

When saw the factor educational level, completed primary and secondary educational level makes the number of children ever born increased. Research did in Central Kenya using Kenya DHS showed that completed primary level education, completed secondary level education and completed higher level education decrease number of children ever born by $26 \%, 25 \%$ and $40 \%$ respectively. Other research conducted in Egypt showed that education status revealed that higher or secondary educated women has 2 less children than less educated women which means when the educational status increase, number of children ever born became decreased. In the above all mentioned research education had decrement effect on the number of children ever born $[21,22]$.

In the result, living rural increase the number of children ever born when compared to living urban. Research done on EDHS 2011 on determinant of fertility analysis in Ethiopia which shows living in rural increase the number of children ever born by $4.9 \%$ compared with women living in urban. The finding also supported by the researches which was conducted in Kenya DHS showed that living rural increase the number of children by $10 \%$. This may due to different factors such as most of the time the accessibility and awareness of family planning method is not well in rural than urban. In developed countries special people living in rural considering their children as their property (wealth) which means they believe that they are their care giver and source of income while they became aged [21, 23].

Factors related to women occupation category showed as a significant factor for the decline number of children ever born in Ethiopia. Women work clerical job sales, service and skilled manual decrease the number of children ever born in Ethiopia. Research conducted in Botswana revealed that working as employment decrease number of children ever born by $8 \%(0.92)$ compared to those who did not working. Other research conducted in Kenya reported that when the women have no work experience increase the number of children when compared with that of women have their own work. This difference results happened due to the research conducted in different geographical area [21].

When see the wealth index factor increasing wealth index has effect to decrease the number of children ever born in 
Ethiopia. Research conducted in Kenya also showed that being middle and rich wealth index family, decrease the number of children ever born by $7 \%$ and $17 \%$ respectively when compared with that of poor. This finding had similar idea with the finding of research which was did in Ghana. I.e.; when the house hold had high wealth index and educated their number of children ever born were decreased. In general, in many countries having fewer children has come about as $\mathrm{s}$ response to increased life expectancy, reduced childhood mortality, improve female literacy and independence, and urbanization that all results from increased GDP per capita. The economic theories about declining fertility postulate that people earning more have higher opportunity cost if they focus on childbirth and parenting rather than continuing their career, that women who can economically sustain themselves have less incentive to become married, and that higher income parents value quality over quantity and so spend their resources on fewer children [17].

Religion such as Protestant, Muslim, Traditional and category of other religion increase the number of children ever born in Ethiopia. This result can supported by analysis done based on EDHS 2011 on the title of determinants of fertility in Ethiopia, religion shows that Muslim women have $1.7 \%$ higher fertility when compared to women with traditional beliefs. But, Women with Orthodox (-0.04) have lowest fertility when compared to women being traditional religion. Researched did in Nigeria fertility change across religion which was Muslim group increase their fertility rate over the two inter survey years. Other surveys which done in United States found that women who reported religion as "very important" in their every lives had higher fertility. Even though the research was done qualitatively the result supports this research finding [23].

In this analysis using family planning decrease the number of children ever born in Ethiopia. Other analysis done in Kenya, Indonesia, and Ukraine indicates that use of family planning decrease number of children ever born by $14 \%, 21 \%$ and $29 \%$ respectively. The difference of the result may be due to geographical location, the population characteristics and the methods used to did the research [24].

On the other result of this research the fertility preference also had statistically significant factor on the number of children ever born. The decrement effect that indicated in the result were, women prefer no more children decrease the number of children ever born. This may occur due women may have large number of children on the time of survey. This result can be agree with literatures which indicated that, currently, 214 million women in developing countries who wish to avoid pregnancy. This leads women and couples who wish to have fewer children and able to determine the size of their families in large part [15].

\section{Conclusions}

Women completed primary and secondary education level, family wealth index and engaged women on job, gaining information about family planning and using of family planning methods decrease the number of children ever born in Ethiopia. On the other hand living in rural increase the number of children ever born in Ethiopia. In Muslim, Protestant, Traditional and category of other religion there were variation for the increment of number of children ever born.

\section{List of Abbreviations}

A. $I R R=$ Adjusted Incidence Rate Ratio

C. $I R R=$ Crude Incidence Rate Ratio

CEB- Children Ever Born

CI- Confidence Interval

CSA- Central Statistics Agency

DHS- Demography Health Survey

EA- Enumeration Area

EDHS- Ethiopia Demography and Health Survey

ETB- Ethiopian Birr

Figure - Figure

FP- Family Planning

ICC- Intra-class Correlation

IRR- Incidence Rate Ratio

menbreg- multilevel mixed effect negative binomial regression

nbreg- negative binomial regression

NDHS- National Demography and Health Survey

PHC- Population and Housing Census

PSU- Primary Sampling Unit

Ref - Reference

UN- United Nation

UNFP- United Nation Food Program

WHO- World Health Organization

AIC- Akaike Information Criteria

\section{Ethics Approval and Consent to Participate}

Ethical clearance was gained from Debre Markos University Health Science College which was approved by research ethicas review committee. This research was done after gaining legal permission that is authorization letter from Demographic and Health Surveys (DHS) Program. Also, the research was done by maintaining the confidentiality and taking full responsibility.

\section{Availability of Data and Materials}

The data for this research is available in STATA form in the corresponding author and can attach any time requested by the journal.

\section{Funding}

The author was the funding source to the design of the study and collection, analysis, and interpretation of data and in writing the manuscript of this research report. 


\section{Authors' Contributions}

The second author had contributed in design, analysis and interpretation of this research.

\section{Competing Interests}

The authors declare that they have no competing interests.

\section{Acknowledgements}

My thanks goes to my advisers Mr. Getiye D. (MPH) and Mr. Likinaw B. (MSc) for giving supportive and genuine idea to do and complete this thesis. Also, I thanks Mr. Tenaw Y. (MPH, PhD. Candidate) and Mrs. Lieltework Y. (MPH). At the end my gratitude includes Debre Markos University College of Health Science to open this chance of attending MPH in Epidemiology.

Finally, I would like to thank DHS program data archivist in order to give permission to access the EDHS 2016 data and all study participants in EDHS 2016.

\section{References}

[1] Pushkar Maitra, S. P., Birth spacing, fertility selection and child survival: Analysis using a correlated hazard model. 2008

[2] MD. ISLAM UDDIN, K. C. B. A. S. S. I., DETERMINANTS OF DESIRED FAMILY SIZE AND CHILDREN EVER BORN IN BANGLADESH. December - 2011. Vol. 57, No. 2.

[3] Vijai Kumar Dwivedi, T. S. a. N. O. A., Factors Affecting Children Ever Born (CEB) in Botswana: Application of Poisson Regression Model. 2016.

[4] UN, world-fertility-patterns-2015. pdf. 2015.

[5] Swartz, L., Fertility transition in South Africa and its implications on the four major population groups. asdf, 2009: p. 487.

[6] Cleland, J., < $\quad$ World-Population-Growth-Past-Present-andFuture. pdf $>$. 2013.

[7] Casterline, J. B. a. J., Fertility Transition: Is sub-Saharan Africa Different? 2014.

[8] United Nations, D. o. E. a. S. A., Population Division, World Population Prospects: The 2015 Revision. 2015. I (Revision).
[9] Phyllis Machio, P., P. Jane Kabubo-Mariara, and P. Anthony Wambugu, The causal effect of early fertility and marriage on education and employment among young women in Kenya*. 2014.

[10] Hari Prasad Upadhyay*, K. R. B., Factors Associated with Children Ever Born: A Case Study of Somadi Village Development Committee of Palpa District, Nepal. 2017. 1: p. $15-29$.

[11] Nations, U., Manual_X INDIRECT TECHNIQUES FOR DEMOGRAPHIC ESTIMATION. 1983.

[12] Central Statistical Agency, A. A., Ethiopia, summary and statistical report of 2007 population and housing census of Ethiopia. 2007.

[13] Shrestha, S. L., Poisson Model for Linking Children Ever Born with Some Key Predictor Variables in Nepalese Women. 2013.

[14] LIBERIA INSTITUTE OF STATISTICS AND GEOINFORMATION SERVICES (LISGIS) MONROVIA, L., $<$ Fertility and Marriage pattern $>$. SEPTEMBER 2011.

[15] Evans, H., What fertility rates in Africa tells us about Global development. Population Connection, 2018.

[16] www.wikipedia.income.

[17] http://www.economic/theories/postulates/fertility/decline/.

[18] Ethiopia, N. P. P. o., National Population Policy of Ethiopia. 1993.

[19] http://u.osu.edu/ockerman.2/files/2014/03/,<Ethiopia$1 \mathrm{i} 7$ cwe $5>$. 2014.

[20] Central Statistical Agency, A. A., Ethiopia, ETHIOPIA Demographic and Health Survey Key Indicators Report. 2016.

[21] MATHENGE, G. W. and J. ITROMID, The Role of Education in Influencing Fertility levels, women in central province, kenya Statistics South Africa, 2010.

[22] Radovich, E., et al., Rising up: Fertility trends in Egypt before and after the revolution. PLoS One, 2018. 13 (1): p. e0190148.

[23] Ayele, D. G., Determinants of fertility in Ethiopia. African Health Sciences 2015. Vol 15 (2).

[24] Winfrey, J. S. a. W., The effects of family planning and other factors on fertility, abortion, miscarriage, and stillbirths in the Spectrum model. BMC Public health, 2017. 